\title{
Plexiform Neurofibroma During Pregnancy, A Case Report From Nepalgunj Medical College Teaching Hospital, Kohalpur
}

\author{
Sharma $\mathrm{N}^{1}$, Rawat BC D ${ }^{2}$
}

\begin{abstract}
:
Plexiform neurofibromas are rare variant (30\%) of neurofibromatosis type 1 (NF-1) in which neurofibromas arise as large deforming masses from multiple nerve endings involving also connective tissues and skin folds.We report a case of 24 years old female, second gravida and one parity with diagnosis of plexiform neurofibromatosis made in previous pregnancy with remission of symptoms after pregnancy and accentuation during second pregnancy with positive pregnancy outcome.
\end{abstract}

INTRODUCTION: Neurofibromatosis type 1 (NF-1) is an autosomal dominant genetic condition. It has incidence of approximately 1 in 3000. It is caused by mutation of NF-1 gene, which is located at chromosome 17q11.2. It is characterized by café-au-lait macules, axillary freckling, tumor like growth along nerves known as neurofibromas ${ }^{1}$. NF-1 gene produce protein named neurofibromin which is responsible for regulation of cell growth. Mutated NF-1 cannot produce Neurofibromin hence cell growth will be unregulated and uncontrolled.

Plexiform neurofibromas are rare variant (30\%) of neurofibromatosis type 1 (NF-1) in which neurofibromas arise as large deforming masses from multiple nerve endings involving also connective tissues and skin folds.

Half of people with neurofibromas inherit disease. There are some small studies that support tumor growth in pregnancy likely secondary to the increased level of hormones. Further, there has been documented rapid growth in preexisting tumors that have caused life-threatening and sometimes even fatal complications ${ }^{2}$. Most women with NF-1 have good pregnancy outcome but careful monitoring is needed. Neurofibromatosis can't be cured fully but treatment is available for symptomatic relief. Early diagnosis and treatment of symptoms calls for good prognosis in pregnancy. Here we report on a pregnant woman who had multiple neurofibromas beginning after mid of first pregnancy leading to diagnosis of neurofibromatosis type 1 . The patient had decreased in the size of neurofibromas after first pregnancy and increase in size of existing neurofibromas in second pregnancy.

\section{CASE REPORT}

A 24 years old female G2P1 at 38 weeks of gestation with regular antenatal checkup done outside presented to hospital with chief complaint of pain lower abdomen on and off. She had past medical history of neurofibromatosis type 1.

1. Dr. Nirmala Sharma
2. Dr. Durga B.c.

\section{Address for correspondence:}

Dr. Nirmala Sharma

Lecturer

Department of Obstetrics \& Gynaecology

Neplagunj Medical College \& Teaching Hospital

Kohalpur, Banke, Nepal

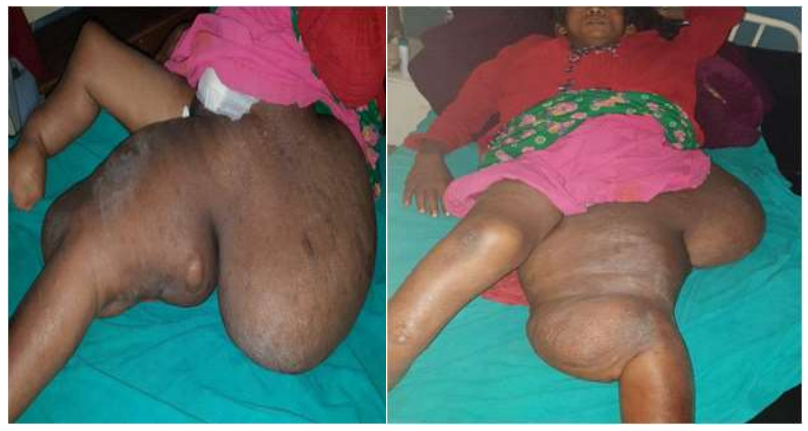

But she denies family history of same. Similarly, she does not have past history of hypertension, seizure, tuberculosis or other significant diseases.

The patient states that she had been diagnosed with NF 1 in her previous pregnancy 4 years back. Per her saying she had multiple eruptions of papules and nodules throughout her body in first trimester of first pregnancy. Thereon progressive enlargement of such nodules in her back and lower limb giving rise to massive enlargement of legs and inability to walk in third trimester. However, pregnancy was uneventful. Induction done after 40 weeks of gestation but landed up in caesarean section due to prolong labor. Puerperium was uneventful, she noticed gradual regression of enlarged limbs and back thereafter. 
In this pregnancy, she had no other complaints despite gradual enlargement of existing neurofibromas predominantly in sacral region and left lower limb to the extent she was rendered incapable of walking on reaching third trimester. There is no history of pain, no headache, no raised blood pressure throughout pregnancy, no visual changes nor any neurological symptoms. All the lab tests were within normal limits. During admission she was not in labor and ultrasonography revealed single live fetus of 32 weeks gestation. She was kept under observation and betamethasone started for fetal lung maturity. But she developed per vaginal leaking after 12 hours and liquor was moderately meconium stained. So she was taken for caesarean section with delivery of $1.9 \mathrm{~kg}$ female with Apgar score of 5/10 and $7 / 10$ at 1 and 5 minutes. Placenta was normal. Baby was kept on NICU for observation and given to mother after few hours. Post-operative recovery was uneventful and was discharged home after 7 days. During discharge patient was counselled about the risks of transforming to malignancy and was suggested for follow up if symptoms like, increase in size of tumor, change in consistency or pain occurs.

\section{DISCUSSION}

The interaction of neurofibromin (NF) with other membrane cellular proteins such as proteoglycans, intermediate actin filaments, and tubulin promotes the alteration in the regulation that leads to the development of this syndrome ${ }^{3}$.Same as other neurodevelopmental disorders, some identified mutations which encode for the RAS/mitogen-activated protein kinase pathway is activated from the protein kinase pathway. The NF1 gene is considered a gene suppressor which when altered does not produce enough neurofibromin to assure and regulate cellular growth (haploinsufficiency) ${ }^{5}$. However many cases require another event (second hit mutation) for the manifestation of clinical signs and symptoms of the disease. Hormone changes as in pregnancy or puberty leads to second hit mutation in these individuals and development of neurofibromas ${ }^{6}$. The growth and mass effect of a neurofibroma during puberty or pregnancy should be monitored due to the possibility of the appearance of new symptoms in patients diagnosed with NF-1.

Malignancy is a concern in patients with neurofibromatosis. Large plexiform neurofibromas are at increased risk of transforming into malignant peripheral nerve sheath tumor (MPNST) ${ }^{7}$. These tumors are resistant to chemotherapy and radiation. They grow from nerve fascicles along the length of nerve and are locally destructive to bones and surrounding tissues. During the period of growth, if tumor becomes destructive, surgery is the best means of cure.
The patient described above had similar history in the past. Aggravation of symptoms in pregnancy and regression post pregnancy.

\section{CONCLUSION}

Surgery is the mainstay of treatment. Growth of lesion in pregnancy puts obstetrician more in confusion as to whether it is due to hormones or some malignant transformation. So work up must be done as early as possible. Radiological examination like MRI is of limited help. Taking multiple biopsies form lesion can detect the transformation. Instituting treatment early decreases mortality as malignancy is the main cause of morbidity and mortality in NF1 population.

\section{REFERENCES}

1. Evans DG, Howard E, Giblin C, et al. Birth incidence and prevalence of tumor-prone syndromes: estimates from a UK family genetic register service. Am J Med Genet A 2010; 152A:327-332.

2. The role of steroid hormones in the NF1 phenotype: focus on pregnancy. Roth TM, Petty EM, Barald KF. Am J Med Genet. 2008;146: 1624-1633.

3. Bonneau F, D'Angelo I, Welti S, Stier G, Ylänne J, Scheffzek $K$. Expression, purification and preliminary crystallographic characterization of a novel segment from the neurofibromatosis type 1 protein. Acta Crystallogr D Biol Crystallogr. 2004;60(Pt 12 Pt 2):2364- 7. [PubMed] [Google Scholar]

4. Tidyman WE, Rauen KA. The RASopathies: Developmental syndromes of Ras/MAPK pathway dysregulation. Curr Opin Genet Dev. 2009;19:230-6. [PMC free article] [PubMed] [Google Scholar]

5. Jouhilahti EM, Peltonen S, Heape AM, Peltonen J. The pathoetiology of neurofibromatosis 1. Am J Pathol. 2011;178:1932-9. [PMC free article] [PubMed] [Google Scholar

6. Jouhilahti EM, Peltonen S, Callens T, Jokinen E, Heape AM, Messiaen L, et al. The development of cutaneous neurofibromas. Am J Pathol. 2011;178:500-5. [PMC free article] [PubMed] [Google Scholar]

7. Malignancy in neurofibromatosis type 1. Korf BR. Oncologist. 2000;5:477-485. [PubMed] [Google Scholar] 